www.jmscr.igmpublication.org Impact Factor 5.244

Index Copernicus Value: 83.27 ISSN (e)-2347-176x ISSN (p) 2455-0450 crossref DOI:_http://dx.doi.org/10.18535/jmscr/v4i8.41

\author{
Journal Of Medical Science And Clinical Research \\ IGM Publication \\ An official Publication of IGM Publication
}

\title{
Knowledge of Sterlisation Protocol in Dental Office among Dental Practioners
}

\author{
Authors \\ Jayashree, Dr. Senthilnathan \\ Saveetha University \\ Email: jayashreearun95.ja@gmail.com
}

\begin{abstract}
ABSTARCT
AIM: The aim of the study is to evaluate the knowledge of sterlisation protocol in dental office among general dental practioners.

MATERIALS AND METHODS: A questionnaire was designed to obtain information about knowledge of sterlisation among dental professionals. The sample size was 50.The questionnaires were filled by the dentists. The questions include knowledge about sterlisation, and sterlisation protocol.

RESULTS: The most common method of sterilization reported by the respondents was autoclaving $74 \%$. In this dry heat $6 \%$ was used by and boiling method by 20\%. The use of disinfectants was higher with phenolbased disinfectants, which is 56\% in this study. According to the survey 54\% do sterlise files whereas $26 \%$ sometimes do. The method of sterlisation used commonly is chemical which is $46 \% .74 \%$ used sterlium after attempting a patient. $46 \%$ sterlise their instruments once daily and $40 \%$ sterlise twice daily. $46 \%$ disinfect sometimes or the clinic is not disinfected. Whereas, $16 \%$ do disinfect which is comparatively less in number. Study says $78 \%$ chose automated method as the best method of cleaning instruments. 58\% sterlise their handpiece and burs while and 36\% sometimes and 6\% doesnot sterlise their handpiece and burs. $76 \%$ doesnot sterlise suction tips that is being used.
\end{abstract}

\section{INTRODUCTION}

Oral and dental diseases have become a major public health concern in both developed and developing countries. ${ }^{[1]}$ The dental health-care settings is an environment where disease transmission occurs easily. Prevention of infection and control is an important part of safe patient care. Concerns about the possible spread of bloodborne diseases, and the impact of emerging, highly contagious respiratory and other illnesses, require practitioners to establish, evaluate, continually update and monitor their infection control strategies and protocols. ${ }^{[2]}$ Strategies to prevent dental patient infections have focused on disinfection and sterilization.

The use of procedures to control infection and universal precautions in dental surgeries is effective in preventing microbial pollution and cross-contamination, and is strongly supported by organizations such as the Centers for Disease Control and Prevention, the American Dental Association, schools of dentistry, and many other health agencies and professional associations ${ }^{[3]}$. Universal precautions consider that all patients have to be accepted as an infectious patient and apply these precautions to all patients ${ }^{[4]}$. 
However, infection control policies in developing countries have not been widely documented ${ }^{[5]}$. Most hospitals have no infection control programs due to the lack of awareness of the problem or absence of properly trained personnel ${ }^{[6]}$

These studies indicate that there are gaps in some dentist's knowledge regarding modes of transmission of infectious diseases so the objective of this study was to increase the awareness and importance of sterilization in reducing the communicable diseases among dental faculty and to identify the areas where improvements can be made in dental OP.

\section{MATERIALS AND METHODS}

A questionnaire was designed to obtain information about knowledge of sterlisation among dental professionals. The sample size was 50.The questionnaires were filled by the dentists. The questions include knowledge about sterlisation, and protocol followed in their practice.

A self-administered, close-ended questionnaire was given to the voluntary respondents and the information about their knowledge, practices and attitude was evaluated. Questionnaire elicited information on demography and perception on the disinfectants in the regular dental practice, methods of sterilization and knowledge about the waste management.

1. What kind of sterilization equipment used in your clinic

a. Autoclave b. Hot air oven c. Boiler

2. What type of disinfectant used in your clinic

a. Halogen based disinfectant b. Phenol based disinfectant c. Alcohol based disinfectant

3.Do you sterilize your root canal files

a. Yes b.no c. sometime

4. If yes how do u sterilize your files

a. Using glass bead sterliser b. using chemicals methods c. using spirit

5. Do you use hand sterilization agent sterileum after attempting the patient

a. Yes b.no
6. How often you sterilize your instruments in your clinic

a. Once daily b. once in a week c. twice in a day

7. Is disinfection procedure followed in your clinic

a. Yes b.no c. sometime

8. which is the best method for cleaning instruments

a. Manual b. automated

9.Do you sterilize your handpiece and burs?

a. Yes b.no c. sometimes

10.Do you sterilise your suction tips?

a. Yes b.no

\section{RESULTS}

The most common method of sterilization reported by the respondents was autoclaving $74 \%$, which is almost equal to previous studies (Sofola and Savage $84.1 \%$, Sote $92 \%$ and Omolara $79.2 \%$. In this dry heat $6 \%$ was used by and boiling method by $20 \%$. The use of disinfectants was higher with phenol-based disinfectants, which is $56 \%$ in this study. According to the survey $54 \%$ do sterlise files whereas $26 \%$ sometimes do. The method of sterlisation used commonly is chemical which is $46 \% .74 \%$ used sterlium after attempting a patient. $46 \%$ sterlise their instruments once daily and $40 \%$ sterlise twice daily. $46 \%$ disinfect sometimes or the clinic is not disinfected. Whereas, $16 \%$ do disinfect which is comparatively less in number. Study says $78 \%$ chose automated method as the best method of cleaning instruments. 58\% sterlise their handpiece and burs while and 36\% sometimes and 6\% doesnot sterlise their handpiece and burs. $76 \%$ doesnot sterlise suction tips that is being used.

\section{DISCUSSION}

Due to the nature of their profession, dentists and dental assistants should not forget the risk of treating patients with probability of infectious diseases. Dentists, dental assistants and patients may be exposed to pathogenic microorganisms localized in oral cavity and respiratory tract including cytomegalovirus (CMV), $\mathrm{HBV}, \mathrm{HCV}$, 
herpes simplex virus, HIV, Mycobacterium tuberculosis, staphylococci, streptococci and other viruses and bacteria ${ }^{[7]}$ These microorganisms could be transmitted to the dental health care professionals by direct contact with a patient's saliva, blood, skin, and oral secretions, or by indirect contact through injuries caused by sharp contaminated instruments, or by droplet infection from aerosols or spatter ${ }^{[7,8,9]}$.

Increased awareness about risks of transmission of infection through blood and saliva has led to increased use of protective barrier techniques. The most common method of sterilization reported by the respondents was autoclaving $74 \%$ which is almost equal to previous studies (Sofola and Savage $84.1 \%$, Sote $92 \%$ and Omolara $79.2 \%$. In this dry heat $6 \%$ was used by and boiling method by $20 \%$. The use of disinfectants was higher with phenol-based disinfectants, which is $56 \%$ in this study. According to the survey 54\% do sterlise files whereas $26 \%$ sometimes do. The method of sterlisation used commonly is chemical 1. Very few of the respondents had a poor knowledge about the proper sterilization. When asked about an organization about waste management $52.2 \%$ was unaware of such organization or institute. $56.2 \%$ the staff were vaccinated. This study concluded that knowledge of sterlisation among different levels of dental professionals is adequate but more awareness needs to be made for better future.

\section{CONCLUSION}

This study concludes that knowledge of sterlisation among different levels of dental professionals is adequate but more awareness need to be made for better infection control in the future.

\section{REFERENCE}

1. Sterilizations and Disinfection. Manual of Infection Control Procedure 2nd ed. London (Greenwich Medical Media 2003.
2. Guidelines on infection prevention and control in the dental office, Royal College of Dental Surgeons Ontario. 2012.

3. Centers for Disease Control and Prevention. Recommended infectioncontrol practices for dentistry. MMWR Morbid Mortal Wkly Rep. 1993; 42:112. [PubMed]

4. Centers for Disease Control and Prevention. Update: transmission of HIV infection during invasive dental procedures-Florida. MMWR Morbid Mortal Wkly Rep. 1991; 40:377381. [PubMed]

5. Morris E, Hassan FS, Al Nafisi A, Sugathan TN. Infection control knowledge and practices in Kuwait: a survey on oral health care workers. Saudi Dent J. 1996; 8:19-26.

6. Sobayo EL. nursing aspects of infection control in developing countries. J Hosp Infect. 1991; 18(Suppl A): 388391. [PubMed]

7. Bolyard EA, Tablan OC, Williams WW, Pearson ML, Shapiro CN, Deitchman SD. Guideline for infection control in health care personnel, 1998. Hospital Infection Control Practices Advisory Committee. Am J Infect Control. 1998; 26:289-354. [PubMed]

8. Centers for Disease Control and Prevention. Recommended infectioncontrol practices for dentistry. MMWR Morbid Mortal Wkly Rep. 1993; 42:112. [PubMed]

9. Verrusio AC, Neidle EA, Nash KD, Silverman S, Jr, Horowitz AM, Wagner KS. The dentist and infectious diseases: a national survey of attitudes and behavior. $\mathrm{J}$ Am Dent Assoc. 1989; 118:553562. [PubMed] 